\title{
Effect of Shift-Work on Hypertension Among Factory Workers in Ethiopia
}

\author{
Henok Asresahegn Asfaw ${ }^{1, ~ *, ~ E p h r e m ~ M a m o ~ G e b r e h i w o t ~}{ }^{2}$, Solomon Shiferaw ${ }^{3}$ \\ ${ }^{1}$ Department of Epidemiology and Biostatistics, College of Health Sciences, Jigjiga University, Jijiga, Ethiopia \\ ${ }^{2}$ Departments of Public Health, Faculty of Health Sciences, Assosa University, Assosa, Ethiopia \\ ${ }^{3}$ School of Public Health, College of Health Sciences, Addis Ababa University, Addis Ababa, Ethiopia
}

Email address:

hasresahegn01@gmail.com (H. A. Asfaw), ephremmamo@yahoo.com (E. M. Gebrehiwot), soloshi@yahoo.com (S. Shiferaw)

\section{To cite this article:}

Henok Asresahegn Asfaw, Ephrem Mamo Gebrehiwot, Solomon Shiferaw. Effect of Shift-Work on Hypertension Among Factory Workers in Ethiopia. American Journal of Clinical and Experimental Medicine. Vol. 3, No. 4, 2015, pp. 142-148. doi: 10.11648/j.ajcem.20150304.13

\begin{abstract}
Background: Shift work is associated with several health problems, possibly due to an impairment of biological rhythms. Some studies reported that changes in blood pressure regulation among shift workers could lead to chronic hypertension. So this study aimed to determine and compare the level of and risk factors for hypertension among shift and day time workers. Methods: A comparative cross-sectional study of 830 current factory workers (413 shift workers and 417 day time workers) who have worked for at least five years was conducted in Wonji Shoa sugary factory, Ethiopia. Data were collected using a pretested structured questionnaire, and blood pressure was measured using standardized instruments by trained clinical nurses. Hypertension was defined as having Systolic BP $\geq 140 \mathrm{mmHG}$ or Diastolic BP $\geq 90 \mathrm{mmHG}$ or reported use of regular anti-hypertensive medications prescribed by professionals for raised BP. Multiple logistic regressions were fitted and Odds ratios with $95 \%$ confidence intervals were calculated to identify independently associated factors. Results: shift work, older age, higher income quintile, and family history of hypertension were found to be independently associated with Hypertension. The prevalence of hypertension was significantly higher among shift workers compared to daytime workers $(42.9 \%$ versus $30.0 \%$; p-value $<0.05)$ ). Multivariate analysis revealed the odds of being hypertensive among shift workers persists even after controlling for potential confounders including age, income, and family history of hypertension. [AOR (95\% $\mathrm{CI})=1.48(1.02,2.14)]$. Shift workers were also significantly more likely to be smokers compared to day-time workers $(6.5 \%$ versus $13.1 \%$; $p$-value $<0.001)$. Conclusions: shift work, older age, higher income quintile, and family history of hypertension were found to be independently associated with Hypertension. The finding calls for institutionalization of efficient health screening and regular checkups as well as interventions promoting healthy lifestyles among shift workers.
\end{abstract}

Keywords: Hypertension, Shift Work, Factory Workers

\section{Introduction}

Shift work refers to work patterns that extend beyond the conventional 8-hour work day and that potentially disrupt workers' normal biological and/or social diurnal rhythms. The varieties of shift work include permanently displaced work hours, rotating shift work, and unscheduled work hours [1]. Of these, rotating night shifts are particularly disruptive for sleep, wakefulness, eating patterns, and social activities[2]. Rotating night shifts also are associated with reduced job-related performance and higher levels of perceived stress $[3,4]$.

Shift work is associated with several health problems, possibly due to an impairment of biological rhythms. In particular, an increased risk of coronary heart disease (CHD) among shift workers with a direct association between relative risk for CHD and time of exposure to shift work has been reported in previous studies [5, 6].

Additionally, several studies have reported a higher prevalence of coronary risk factors among rotating shift workers, including increased cigarette consumption, higher blood pressure, and increased serum cholesterol, glucose, and uric acid levels and urinary adrenaline excretion[7].

Despite the biological plausibility and evidence from short term studies, there are very few studies that reported changes in blood pressure regulation among shift workers could lead to chronic hypertension [8]. For instance, in a Japanese cohort study, habitual shift workers of a steel company had 
higher systolic and diastolic blood pressure than habitual daily workers [7]. In contrast the Finnish Twin Cohort [9], and a survey from Brazil [10] showed no association between the usual period of work and incidence and prevalence of hypertension respectively.

Until recently, the prevention and control of hypertension has not received due attention in many developing countries including Ethiopia; although it is one of the most modifiable risk factors for cardiovascular diseases. However, awareness about treatment and control of hypertension is extremely low among developing nations including Ethiopia, especially in relation to work and work related problems like shift work. In these countries health care resources are overwhelmed by other priorities including HIV/AIDS, tuberculosis, and malaria [19].

However, recent evidences indicate that hypertension and raised blood pressure are increasing partly because of the increase in risk factors including smoking, obesity, and harmful use of alcohol and lack of exercise [19]. But, little is known about the magnitude and determinants of hypertension in relation to in the shift workers in most developing countries including Ethiopia.

Even though there are no recent data on the number of shift workers in Ethiopia and other low income countries, it is clear that significant segment of the workforce is working in this setting. With many grand development initiatives and increasing industrialization, the number of shift workers is bound to increase to meet the needs for time-flexibility of the workforce that is key to optimize productivity and competitiveness [28]. Hence, it is timely to explore the burden and differentials of hypertension among shift and day time workers in Ethiopia and design appropriate strategies.

Thus, this study aimed to identify the effect of shift work on hypertension among factory workers in Ethiopia.

\section{Methods and Materials}

\subsection{Study Design and Participants}

A comparative cross-sectional study was conducted among randomly selected day time and shift workers in Wonji Shoa sugar factory; one of the oldest agro industries in Ethiopia. Study participants were permanent employees of the sugar factory who have been working there at least for 5 years and those who had eight hour shift in a regular manner. Workers were stratified by their work pattern as shift and day time workers, and Study participants were selected from each group using simple random sampling. Excluding subjects with incomplete information $(n=6)$ the final sample size included 830 (413 shift workers and 417 day time workers). All shift workers were working three shifts rotating every week. This study was conducted in accordance with the STEP- wise approach of the World Health Organization (WHO) for NCD surveillance in developing countries [11]. The approach has three levels: (1) questionnaire to gather demographic and behavioral information, (2) physical measurements, and (3) biochemical tests. The present study used the first 2 steps; questionnaire survey and anthropometric and blood pressure measurement.

\subsection{Data Collection and Variable Specification}

Participants were interviewed by trained interviewers using the WHO STEPS-structured questionnaire. In accordance with the STEPS manual, questions related to alcohol and substance use were tailored to reflect the local context of Ethiopia [11]. The questionnaire was first written in English, translated into Amharic by experts, and translated back into English by a panel of professionals who speak both languages. The questionnaire was pretested before the initiation of the study and contained information regarding socio-demographic characteristics, tobacco and alcohol use, and nutritional status. A three-days training of the contents of the STEPS questionnaire, data collection techniques, and ethical conduct of human research was provided to research interviewers prior to the commencement of the study.

Blood pressure (BP) was measured using a digital measuring device with participants sitting after resting for at least five minutes. Two BP measurements were taken with at least three minute intervals between consecutive measurements. The mean systolic and diastolic BP from the first and second measurement was analyzed [11]. The measurement was taken with each subject sitting on a chair and supported hand. The measurement was taken early in the morning from $7 \mathrm{am}-10 \mathrm{am}$ and in the afternoon after $4 \mathrm{pm}$ in a calm environment. Hypertension was defined as mean systolic blood pressure (SBP) $\geq 140 \mathrm{mmHg}$ or mean diastolic blood pressure $(\mathrm{DBP}) \geq 90 \mathrm{mmHg}$.

All subjects provided informed consent, and all research protocols were approved by the Institutional Review Boards of Addis Ababa university school of public health, Addis Ababa, Ethiopia.

\subsection{Statistical Analyses}

Data were entered into EPI INFO (Version 3.5.1), and exported to SPSS (Version 16.0) for statistical analysis. We first explored frequency distributions of socio demographical and behavioral characteristics of subjects and Descriptive statistics was used to summarize and present the information in the form of mean, median, percentages and tables with $95 \%$ confidence intervals for prevalence estimates. Binary logistic regression analysis was used to examine the association between shift work and hypertension adjusting for other potential confounders. Both crude and adjusted odds ratio are presented with a $95 \%$ confidence interval. A p-value of less than 0.05 was used to define statistical significance.

\section{Results}

Demographic and lifestyle characteristics of the study population are provided in Table 1. Four hundred thirteen $(49.8 \%)$ of the respondents were shift workers with shift to day time workers ratio to of $1: 1$. Six hundred seventy nine $(81.8 \%)$ of the participants were males. Males constitute 
$378(91.5 \%)$ and $301(72.2 \%)$ among shift and non-shift workers respectively. Non shift workers were significantly more likely to be younger than night shift workers (mean (sd) age $=39 \pm 10$ years versus $42 \pm 10$ years; $p$-value $<0.01)$. Regarding educational status, Non shift workers were significantly more likely to have tertiary (diploma and above) education compared to shift workers $(32.2 \%$ versus $19.4 \%$; $p$ value $<0.001)$. Majority of shift workers $(59.8 \%)$ worked for more than 15 years. Only ninety six $(23.0 \%)$ day time workers and 59(14.0\%) of shift workers belong to the highest wealth quintile.

Table 1. Socio-demographic characteristics of day time and shift workers in Wonji Shoa sugar factory, Ethiopia, January 2012 ( $n=830)$.

\begin{tabular}{|c|c|c|c|c|}
\hline \multirow{2}{*}{ Variable } & \multirow{2}{*}{$\begin{array}{l}\text { Non-shift workers } \\
\text { No }(\%)\end{array}$} & \multirow{2}{*}{$\begin{array}{l}\text { Shift workers } \\
\text { No }(\%)\end{array}$} & \multirow{2}{*}{$\begin{array}{l}\text { Total } \\
\text { No }(\%)\end{array}$} & \multirow{2}{*}{ P-Value } \\
\hline & & & & \\
\hline \multicolumn{5}{|l|}{ Sex } \\
\hline Male & $301(72.2)$ & $378(91.5)$ & $679(81.8)$ & \multirow{2}{*}{$<0.001$} \\
\hline Female & $116(27.8)$ & $35(8.5)$ & $151(18.2)$ & \\
\hline \multicolumn{5}{|l|}{ Age } \\
\hline $20-29$ & $80(19.2)$ & $52(12.6)$ & $132(15.9)$ & \multirow{4}{*}{0.001} \\
\hline $30-39$ & $131(31.4)$ & $114(27.6)$ & $245(29.5)$ & \\
\hline $40-49$ & $131(31.4)$ & $128(31.0)$ & $259(31.2)$ & \\
\hline$>50$ & $75(18.0)$ & $119(28.8)$ & 194(23.4) & \\
\hline \multicolumn{5}{|l|}{ Educational status } \\
\hline Primary $(1-8)$ & $136(32.6)$ & $214(51.8)$ & $350(42.2)$ & \multirow{3}{*}{$<0.001$} \\
\hline Secondary (9-12) & $147(35.3)$ & $119(28.8)$ & $266(32.0)$ & \\
\hline Tertiary (more than 12) & $134(32.2)$ & $80(19.4)$ & $214(25.8)$ & \\
\hline \multicolumn{5}{|c|}{ Average monthly income(quintile) } \\
\hline$<600$ ETB & $81(19.4)$ & $91(22.0)$ & $172(20.7)$ & \multirow{5}{*}{0.004} \\
\hline 601-1040 ЕТВ & $81(19.4)$ & $85(20.6)$ & $166(20.0)$ & \\
\hline 1041-1600 ЕТВ & $68(16.3)$ & $96(23.2)$ & $164(19.8)$ & \\
\hline 1601-2400 ЕТВ & $91(21.8)$ & $83(20.1)$ & $174(21.0)$ & \\
\hline $2401-7000$ ЕTВ & $96(23.0)$ & $59(14.0)$ & $154(18.6)$ & \\
\hline \multicolumn{5}{|c|}{ Work experience in the factory } \\
\hline $5-10$ years & $121(29.0)$ & $63(15.3)$ & $184(22.2)$ & \multirow{5}{*}{$<0.001$} \\
\hline $11-15$ years & $80(19.2)$ & $98(23.7)$ & $178(21.4)$ & \\
\hline $16-22$ years & $70(16.8)$ & $67(16.2)$ & $137(16.5)$ & \\
\hline 23-30 years & $85(20.4)$ & $100(24.2)$ & $185(22.3)$ & \\
\hline$>30$ years & $61(14.6)$ & $85(20.6)$ & $146(17.6)$ & \\
\hline \multicolumn{5}{|l|}{ Smoking habit } \\
\hline Smoker & $27(6.50)$ & $54(13.1)$ & $81(9.8)$ & \multirow{2}{*}{0.001} \\
\hline Non smoker & $390(93.5)$ & $359(86.9)$ & $749(90.2)$ & \\
\hline \multicolumn{5}{|l|}{ Alcohol drinking } \\
\hline Yes & $77(18.5)$ & $110(26.6)$ & $187(22.5)$ & \multirow{2}{*}{0.005} \\
\hline No & $340(81.5)$ & $303(73.4)$ & $643(77.5)$ & \\
\hline
\end{tabular}

Figure- 1 shows the prevalence of hypertension among day and shift workers. The overall prevalence of hypertension in the study participants is $36.4 \%$ (95\% CI $33.1 \%$, 39.7\%). Shift workers were significantly more likely to have hypertension than day time workers [177(42.9\%) versus $125(30.0 \%)$; pvalue $<0.001]$.

Among those who had hypertension $73(58.4 \%)$ of day time workers and $115(65.0 \%)$ shift workers were diagnosed during the survey for the first time; the rest $(41.6 \%$ from day time workers and $35.0 \%$ from shift workers) were already on treatment for hypertension. Close to one-third of study participants $(30.8 \%)$ diagnosed to have hypertension had a family history of hypertension, the likelihood being significantly higher among shift workers $(32.8 \%$ versus $28.0 \%$; p-value $<0.001$ ).

Hypertension was significantly higher among males compared to females [38.1\% versus $28.5 \%$, p-value $=0.03$ ] regardless of their work shift status. As expected men working in shifts had significantly higher prevalence of hypertension compared to men who did not work in shifts [42.9\% Vs 32.2\%, p-value 0.032]. It was also found that Hypertension was more prevalent in the age groups of above 50 years which is $54.1 \%$ (49.3\% in day time and $57.1 \%$ in shift workers) followed by $40-49$ years which was $44.0 \%$ (35.1\% in day time workers and $53.1 \%$ in shift workers).

Table-2 shows respondents' characteristics on diet. Consumption patterns of the participants for various food groups were studied using a Food Frequency Questionnaire (FFQ). More than half $581(70.0 \%)$ of respondents [233(56.4\%) and 348(83.5\%) in day-time and shift workers] consumed of three or less meals per day, respectively. About $609(73.4 \%)$ of respondents, $322(77.2 \%)$ of day time workers and $287(69.5 \%)$ of the shift workers, consume vegetables more than once per day. More than half $603(72.7 \%)$ of respondents, $272(65.2 \%)$ of day time workers and $331(80.1 \%)$ of shift workers, claimed that they did consume meat once or 
less per week. Likewise about $521(62.8 \%)$ of respondents, $247(59.2 \%)$ of day time workers and 274(66.3\%) of shift workers, claimed that they did not consume fruits once or less per week.

Table 2. Characteristics of Diet among day and shift workers in Wonji Shoa sugar factory, Ethiopia, January 2012 (n=830).

\begin{tabular}{|c|c|c|c|c|}
\hline \multirow{2}{*}{ Variable } & Non-shift workers & Shift workers & Total & \multirow{2}{*}{ P-Value } \\
\hline & $\mathrm{n}(\%)$ & $\mathrm{n}(\%)$ & n(\%) & \\
\hline \multicolumn{5}{|l|}{ Number of meals per day } \\
\hline$>3$ per day & $180(43.6)$ & $69(16.5)$ & $249(30.0)$ & \multirow{2}{*}{0.001} \\
\hline$\leq 3$ per day & $233(56.4)$ & $348(83.5)$ & $581(70.0)$ & \\
\hline \multicolumn{5}{|c|}{ Intake of bread and cereals per day } \\
\hline More than once & $131(31.4)$ & $165(40.0)$ & $296(35.7)$ & \multirow{3}{*}{0.013} \\
\hline Once or Less than once & $286(68.6)$ & $248(60.0)$ & $534(64.3)$ & \\
\hline \multicolumn{4}{|c|}{ Intake of vegetable per week } & \\
\hline More than once & $322(77.2)$ & $287(69.5)$ & $609(73.4)$ & \multirow{2}{*}{0.012} \\
\hline Once or Less than once & $95(22.8)$ & $126(30.5)$ & $221(26.6)$ & \\
\hline \multicolumn{5}{|l|}{ Intake of fruits per week } \\
\hline More than once & $170(40.8)$ & $139(33.7)$ & $309(37.2)$ & \multirow{2}{*}{0.041} \\
\hline Once or Less than once & $247(59.2)$ & $274(66.3)$ & $521(62.8)$ & \\
\hline \multicolumn{5}{|c|}{ Intake of meat and egg per week } \\
\hline More than once & $145(34.8)$ & $82(19.9)$ & $227(27.3)$ & \multirow{2}{*}{$<0.001$} \\
\hline Once or Less than once & $272(65.2)$ & $331(80.1)$ & $603(72.7)$ & \\
\hline \multicolumn{5}{|c|}{ Intake of Milk and products per day } \\
\hline More than once & $195(46.8)$ & $123(29.8)$ & $318(38.3)$ & \multirow{3}{*}{$<0.001$} \\
\hline Once or Less than once & $222(53.2)$ & $290(70.2)$ & $512(61.7)$ & \\
\hline \multicolumn{4}{|l|}{ Intake of fat per week } & \\
\hline More than once & $215(51.6)$ & $142(34.4)$ & $357(43.0)$ & \multirow{2}{*}{$<0.001$} \\
\hline Once or Less than once & $202(48.4)$ & $271(65.6)$ & $473(57.0)$ & \\
\hline \multicolumn{5}{|l|}{ Intake of sugar per day } \\
\hline More than once & $180(43.2)$ & $269(65.1)$ & $449(54.1)$ & \multirow{2}{*}{$<0.001$} \\
\hline Once or Less than once & $237(56.8)$ & 144(34.9) & $381(45.9)$ & \\
\hline
\end{tabular}

The logistic regression analyses showed that shift work, older age, higher income quintile, and family history of hypertension were found to be independently associated with Hypertension. Shift workers were about $48 \%$ more likely to be hypertensive when compared with day time workers $[\operatorname{AOR}(95 \% \mathrm{CI})=1.61(1.23,2.37)]$. Participants at age groups of 40-49 years and above 50 were more than three and half times [AOR $(95 \%)=3.77(1.78,7.74)$ and four times AOR $(95 \%)=4.07(2.00,9.99)]$ more likely to be hypertensive when compared with the age groups of 20-29 years respectively.

Regarding the average monthly income, workers who have higher income quintile were found to be about three times more likely to be hypertensive when compared to workers whose income is in the lower quintile[AOR $(95 \% \mathrm{CI})$ $=3.24(1.78,5.89)]$. Participants who were not alcohol drinkers were $37 \%$ less likely to be hypertensive when compared to Alcohol drinkers [COR $(95 \% \mathrm{CI})=0.63(0.45,0.87)]$.It is also found that study participants who have family history of hypertension were more than two times more likely to be hypertensive when compared with those who do not have family history[AOR $(95 \%)=2.24(1.54,3.26)]$. However, no association was seen between hypertension and smoking, educational status, and nutritional.

Table 3. Correlates of hypertension among factory workers, in Wonji Shoa sugar factory, Ethiopia, January 2012 ( $n=830$ ).

\begin{tabular}{|c|c|c|c|c|}
\hline \multirow{2}{*}{ Variables } & \multicolumn{2}{|c|}{ Hypertension } & \multirow{2}{*}{ Crude OR } & \multirow{2}{*}{ Adjusted OR } \\
\hline & Yes $(n, \%)$ & No $(n, \%)$ & & \\
\hline \multicolumn{5}{|l|}{ Work pattern } \\
\hline Non-shift & $125(30.0)$ & $292(70.0)$ & 1.00 & 1.00 \\
\hline Shift & $177(42.9)$ & $236(57.1)$ & $1.75(1.32,2.33)^{*}$ & $1.61(1.23,2.37)^{*}$ \\
\hline \multicolumn{5}{|l|}{ Sex } \\
\hline Male & $259(38.1)$ & $420(61.9)$ & 1.00 & 1.00 \\
\hline Female & $43(28.5)$ & $108(71.5)$ & $0.39(0.28,0.56)^{*}$ & $0.95(0.61,1.49)$ \\
\hline $20-29$ & $18(13.6)$ & $114(86.4)$ & 1.00 & 1.00 \\
\hline $30-39$ & $65(26.5)$ & $180(73.5)$ & $2.29(1.29,4.05)^{*}$ & $1.91(1.03,3.77)^{*}$ \\
\hline $40-49$ & $114(44.0)$ & $145(56.0)$ & $4.98(2.86,8.67)^{*}$ & $3.77(1.78,7.74)^{*}$ \\
\hline$>50$ & $105(54.1)$ & $89(45.9)$ & $7.47(4.22,13.23)^{*}$ & $4.07(2.00,9.99) * *$ \\
\hline \multicolumn{5}{|l|}{ Educational status } \\
\hline Elementary(1-8) & 131(37.4) & $219(62.6)$ & 1.00 & 1. 00 \\
\hline High school (9-12) & $90(33.8)$ & $176(66.2)$ & $0.85(0.61,1.19)$ & $0.88(0.59,1.32)$ \\
\hline
\end{tabular}




\begin{tabular}{|c|c|c|c|c|}
\hline \multirow{2}{*}{ Variables } & \multicolumn{2}{|c|}{ Hypertension } & \multirow{2}{*}{ Crude OR } & \multirow{2}{*}{ Adjusted OR } \\
\hline & Yes $(n, \%)$ & No $(n, \%)$ & & \\
\hline Diploma & $66(39.3)$ & $102(60.7)$ & $1.08(0.74,1.57)$ & $1.36(0.83,2.25)$ \\
\hline Degree and above & $15(32.6)$ & $31(67.4)$ & $0.81(0.42,1.55)$ & $0.66(0.29,1.49)$ \\
\hline \multicolumn{5}{|c|}{ Average monthly income (in quintile) } \\
\hline$<600 \mathrm{ETB}$ & $38(12.6)$ & $134(25.4)$ & 1.00 & 1.00 \\
\hline 600-1040 ЕТВ & $45(14.9)$ & 121(22.9) & $1.31(0.79,2.16)$ & $1.09(0.64,1.88)$ \\
\hline 1040-1600 ЕТВ & $62(20.5)$ & $102(19.3)$ & $2.14(1.33,3.46)^{*}$ & $1.41(0.81,2.41)$ \\
\hline $1600-2400$ ЕТВ & $70(23.2)$ & $104(19.7)$ & $2.37(1.48,3.80)^{*}$ & $1.46(0.84,2.53)$ \\
\hline$>2400 \mathrm{ETB}$ & $87(28.8)$ & $67(12.7)$ & $4.58(2.83,7.41)^{*}$ & $3.24(1.78,5.89)^{*}$ \\
\hline \multicolumn{5}{|l|}{ Smoking Habit } \\
\hline Current Smoker & $28(34.6)$ & $53(65.4)$ & 1.00 & 1.00 \\
\hline Non smoker & 274(36.6) & $475(63.4)$ & $1.09(0.67,1.77)$ & $1.66(0.95,2.89)$ \\
\hline \multicolumn{5}{|l|}{ Alcohol drinking } \\
\hline Drinker & $84(44.9)$ & $103(55.1)$ & 1.00 & 1.00 \\
\hline Non drinker & $218(33.9)$ & $425(66.1)$ & $0.63(0.45,0.87)^{*}$ & $0.68(0.46,1.02)$ \\
\hline \multicolumn{5}{|l|}{ Family history of hypertension } \\
\hline Yes & $93(30.8)$ & $87(16.5)$ & $2.26(1.61,3.15)^{*}$ & $2.24(1.54,3.26)^{*}$ \\
\hline No & $209(69.2)$ & $441(83.5)$ & 1.00 & 1.00 \\
\hline \multicolumn{5}{|l|}{ Intake of bread and cereals/day } \\
\hline More than once & $115(38.1)$ & 181(34.3) & 1.00 & 1.00 \\
\hline Once or less than once & $187(61.9)$ & $347(65.7)$ & $0.85(0.63,1.14)$ & $0.94(0.68,1.31)$ \\
\hline \multicolumn{5}{|l|}{ Intake of vegetables Per day } \\
\hline More than once & $211(69.9)$ & $397(75.2)$ & 1.00 & 1. 00 \\
\hline Once or less than once & $91(30.1)$ & $131(24.8)$ & $1.31(0.95,1.79)$ & $1.31(0.92,1.87)$ \\
\hline \multicolumn{5}{|c|}{ Intake of milk and milk products per week } \\
\hline More than once & $104(34.4)$ & $213(40.3)$ & 1.00 & 1. 00 \\
\hline $\begin{array}{l}\text { Once or less than once } \\
*=\text { Statistically significant }\end{array}$ & $198(65.6)$ & $315(59.7)$ & $1.28(0.96,1.73)$ & $1.09(0.78,1.57)$ \\
\hline
\end{tabular}

\section{Discussion}

Little information exists concerning the prevalence and epidemiological characteristics of hypertension in subSaharan Africa particularly on the risk of hypertension in shift workers [29]. While there is growing evidence on the prevalence of the hypertension and associated factors among Ethiopians [19-20]. Our findings of high prevalence of hypertension and its components are in part due to the epidemiological and nutritional transition that has occurred globally including in sub-Saharan African countries where lifestyle and behavioral changes, both products of modernization and urbanization, have taken place $[23,26]$.

Findings from this study showed a significantly higher prevalence of hypertension among shift workers compared to their counterparts who do not work on shifts. This pattern is consistent with a similar previous study among shift workers in Malaysia although we found a much higher prevalence of hypertension [13] which might be due to the fact that the Malaysian study excluded known hypertensive and diabetic patients. But, contrary to findings of another study in Brazil among the nurses which showed no significant association between shift work and hypertension [10]. This might be their study did not evaluate the duration of shift work. These biases may have led to underestimation of the association between shift work and hypertension.

An increased susceptibility of shift workers to develop chronic diseases such as hypertension can be explained by the disruption of circadian rhythms, and stress related to changes in normal metabolic functions. There is also some evidence that shift work could be associated with unhealthy behaviors including increase in smoking, drinking alcohol, poor diet, and decrease in physical activity [6,13]. In agreement with previous literature $[14,15]$, the current study has shown that the proportion of smokers and drinkers is significantly higher among shift workers.

Our study has several strengths; first, it used comparative design which allowed more precise estimate and analysis of factors that might influence the risk of hypertension among shift and non-shift workers. Second, it used standard and calibrated instruments to do the measurements in anthropometry and blood pressure with regular checks on the reliability of measurement tools. It is also possible that study participant's under-report socially undesirable behaviors such as smoking, and alcohol drinking [27]; however, it is very likely that this will be similar among shift and non-shift workers. Although it is limited to employees of one factory, the factory has a relatively huge and stable workforce which added to the diversity in terms of socio-demographic structure of respondents and time of exposure and a significant variability in the burden of hypertension and associated factors in a work environment.

In conclusion, shift work, older age, higher income quintile, and family history of hypertension were found to be independently associated with Hypertension. The finding calls for institutionalization of efficient health screening and regular checkups as well as interventions promoting healthy lifestyles among shift workers.

\section{Authors' Contributions}

HA conceived the idea, designed the study, performed statistical analysis and wrote the manuscript. SS participated 
in designing the study, analysis, reviewing and editing the final draft and manuscript. EM participated in reviewing and editing the final draft and manuscript. All authors have approved the final form of the manuscript.

\section{Acknowledgements}

The authors would also like to thank staffs of Wonji Shoa sugar factory administration and all research participants who took part in the study. Our special thanks goes to Dr. Gebeyehu Haile, Medical Director in Wonji Shoa sugar factory hospital and Ato Solomon Abache for their support during data collection.

\section{References}

[1] Pati AK, Chandrawanshi A, Reinberg A: Shift work: Consequences and management. Review article.

[2] Moore-Ede M, Richardson G: Medical implications of shift work. Annu Rev Med1985, 36:607-617.

[3] Coffey L, Skipper J, Jung F: Nurses and shift work effects on job performance and job-related stress. J Adv Nursing1988, $13: 245-54$.

[4] Spiegel K, Leproult R, Van Cauter E: Impact of sleep debt on metabolic and endocrine function. Lancet1999,23(354):1435-9.

[5] McNamee R, Binks K, S Jones D, Faulkner A, Slovak N, Cherry M: Shiftwork and mortality from ischaemic heart disease. Occupational and Environmental Medicine1996,53:367-69.

[6] Wang M, Armstrong B, Cairns T, Key J, Travis R: Shift work and chronic disease: the epidemiological evidence. Occupational Medicine 2011, 61:78-89.

[7] Knutsson A, Akerstedt T, Jonsson B, Scand: Prevalence of risk factors for coronary artery disease among day and shift workers. J Work Environ Health1988, 14:317-21.

[8] Mohd Nazri, S Tengku, M Winn, T: Association of Shift Work and Hypertension among Male Factory Workers in Kota Bharu, Kelantan, Malaysia. Department of Community Medicine. January 2008, 39:1.

[9] A. Tran, B. Gelaye, B. Girma, S. Lemma, Y. Berhane, T. Bekele, et al. Prevalence ofMetabolic Syndrome amongWorking Adults in Ethiopia. International Journal of Hypertension 2011:3.

[10] Sfreddo C, Fuchs SC, Merlo AR, Fuchs FD. Shift work is not associated with high blood pressure or prevalence of hypertension. PLoS one 2010 Dec 14; 5(12).

[11] World Health Organization, "Chronic diseases and health promotion: Stepwise approach to surveillance (STEPS),"2010, http://www.who.int/chp/steps/manual/en/index.html.

[12] A. A. Motala, J. C. Mbanya, and K. L. Ramaiya, "Metabolic syndrome in sub-Saharan Africa," Ethnicity \& disease, vol. 19, no. 2, pp. S2-S8, 2009.

[13] Nazri S, Tengku M, Winn T. The association of shift work and hypertension among male factory workers in Kota Bharu, Kelantan, Malaysia. Southeast Asian J Trop Med Public
Health2008 Jan;39(1):176-83.

[14] Karlsson B, Knutsson A, Lindahl B. Is there an association between shift work and having a metabolic syndrome? results from a population based study of 27,485 people. Occupational and Environmental Medicine2001; 58(11):747-52.

[15] Kivimäki M, Kuisma P, M V, Elovainio M. Does shift work lead to poorer health habits? a comparison between women who had always done shift work with those who had never done shift work. Work and Stress2001;15(1):3-13.

[16] Zhao I, Bogossian F, Song S, Turner C. The Association between Shift Work and Unhealthy Weight: A Cross-Sectional Analysis from the Nurses and Midwives' e-Cohort Study. Journal of occupational and environmental medicine $02 / 2011$; 53 (2):153-8.

[17] R. Sodjinou, V. Agueh, B. Fayomi, and H. Delisle, "Obesity and cardio-metabolic risk factors in urban adults of Benin: relationship with socio-economic status, urbanisation, and lifestyle patterns," BMC Public Health, vol. 8, article 84, 2008.

[18] O. O. Oladapo, L. Salako, O. Sodiq, K. Shoyinka, K. Adedapo, and A. O. Falase, "A prevalence of cardio metabolic risk factors among a rural Yoruba south-western Nigerian population: a population-based survey," Cardiovascular Journal of Africa, vol. 21, no. 1, pp. 26-31, 2010.

[19] F. Tesfaye, P. Byass, and S. Wall, "Population based prevalence of high blood pressure among adults in Addis Ababa: uncovering a silent epidemic," BMC Cardiovascular Disorders, vol. 9, article no. 39, 2009.

[20] F. Tesfaye, N. G. Nawi, H. Van Minh et al., "Association between body mass index and blood pressure across three populations in Africa and Asia," Journal of Human Hypertension, vol. 21, no. 1, pp. 28-37, 2007.

[21] F. Tesfaye, P. Byass, S. Wall, Y. Berhane, and R. Bonita, "Association of smoking and khat (Catha edulis Forsk) use with high blood pressure among adults in Addis Ababa, Ethiopia, 2006," Preventing Chronic Disease, vol. 5, no. 3, article A89, 2008.

[22] R. BeLue, TA Okoror, J Iwelunmor et al., "An overview of cardiovascular risk factor burden in sub-Saharan African countries: a socio-cultural perspective," Global Health, vol. 5, article 10, 2009.

[23] L. Fezeu, E. Minkoulou, B. Balkau et al., "Association between socioeconomic status and adiposity in urban Cameroon," International Journal of Epidemiology, vol. 35, no. 1, pp. 105-111, 2006.

[24] K. S. Reddy and S. Yusuf, "Emerging epidemic of cardiovascular disease in developing countries," Circulation, vol. 97, no. 6, pp. 596-601, 1998.

[25] H. C. Onyegbutulem, P. I. H-Onyegbutulem, M. Reimann, J. Li, S. R. Bornstein, and P. E. Schwarz, "Metabolic syndrome in Africa: an emerging perspective," Hormone and Metabolic Research, vol. 41, no. 2, pp. 75-78, 2009.

[26] D. Kebede, A.Alem,G.Mitikeetal.,"Khat and alcohol use and risky sex behaviour among inschool and out-of-school youth in Ethiopia," BMC Public Health, vol. 5, article no. 109, 2005.

[27] B. Assefa, "Ethiopian trade union report," ILO- East Africa Multi-Disciplinary Advisory Team-Profile of Employment and Poverty in Africa, September 2002, Geneva. 
[28] C. Richard, K. Jay, M. Walinjom, M. George., "Hypertension treatment and control in sub-Saharan Africa: the epidemiological basis for policy,"BMJ. Feb 14, 1998; 316(7131): 614-617. 